\title{
CONF-950129--3
}

\section{DIFFERENCES IN CREEP PERFORMANCE OF A HIPed SILICON NITRIDE IN AMBIENT AIR AND INERT ENVIRONMENTS*}

\author{
A. A. Wereszczak, T. P. Kirkland, and M. K. Ferber \\ High Temperature Materials Laboratory \\ Oak Ridge National Laboratory \\ Oak Ridge, TN 37831-6069
}

\begin{abstract}
High temperature tensile creep studies of a commercially available hot isostatically pressed (HIPed) silicon nitride were conducted in ambient air and argon environments. The creep performance of this HIPed silicon nitride was found to be different in these environments. The material crept faster (and had a consequential shorter lifetime) in argon than in ambient air at $1370^{\circ} \mathrm{C}$ at tensile stresses between 110-140 MPa. The stress dependence of the minimum creep rate was found to be $\approx 6$ in argon and $\approx 3.5$ in air, while the minimum creep rates were almost an order of magnitude faster in argon than in air at equivalent tensile stresses. Differences in the creep performance are explained with reference to the presence or absence of oxygen in the two environments.
\end{abstract}

\section{INTRODUCTION}

Being a non-oxide structural ceramic, silicon nitride is susceptible to both oxidation- and creep-assisted microstructural changes (i.e., damage) when it is mechanically loaded at elevated temperatures in ambient air. However, the activity of oxidation- and creep-assisted damage mechanisms cannot be separately investigated via tests in ambient air. Subjecting silicon nitride to high temperature mechanical tests in an inert environment permits the observation of creep-assisted microstructural changes without the effects from oxidation being active. The separate effects of oxidation and creep generated in ambient air testing can then be deduced from the results of tests in an inert environment. The authors have used this methodology to examine creep and oxidation effects via dynamic fatigue testing of a HIPed silicon nitride in air and inert environments. [1-2] However, the desire in the present study was to utilize tensile testing because the stress state of the specimen cross-section is definitive throughout the history of the test, unlike that of a creeping flexure specimen.

Tensile creep-rupture tests were conducted in the present study on a HIPed silicon nitride in ambient air and argon environments at $1370^{\circ} \mathrm{C}$. The creep performance in both environments was compared. Microstructures were examined using optical and scanning electron microscopy, and X-ray diffraction.

* Research sponsored by the U. S. Department of Energy, Assistant Secretary for Energy Efficiency and Renewable Energy, Office of Transportation Technologies, as part of the Ceramic Technology Project of the Propulsion System Materials Program, under contract DE-AC05-840R21400 with Martin Marietta Energy Systems, Inc.
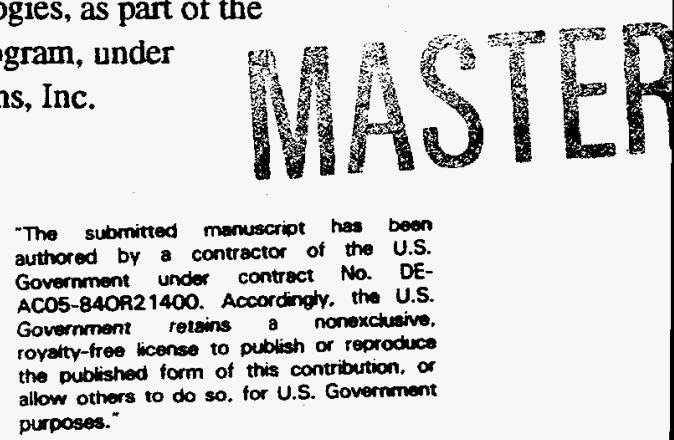


\section{DISCLAIMER}

Portions of this document may be illegible in electronic image products. Images are produced from the best available original document. 
The effects of oxidation- and creep-damage on the creep performance and the evolution of failure were examined.

\section{MATERIALS, TESTING, \& ANALYSIS}

NCX $-5102^{\dagger}$ silicon nitride was tested in this study. The material contained $4 \mathrm{wt} \%$ yttrium oxide that was added as a densification aid. Specimens were near-net-shape pressure slip-cast, glass-encapsulated, and then HIPed at $210 \mathrm{MPa}(30 \mathrm{ksi})$ between $1700-1950^{\circ} \mathrm{C}$. The material was subjected to a proprietary post-HIPing crystallization treatment to promote devitrification of the secondary phase. The as-received microstructure consisted of acicular-shaped grains (typically $\approx 0.7-1.5 \mu \mathrm{m} \times 4-10 \mu \mathrm{m})$ mixed with equiaxed grains $(\approx 1 \mu \mathrm{m}$ diameter). X-ray diffraction (XRD) showed $25-30 \%$ residual $\alpha-S_{3} \mathrm{~N}_{4}$ to be present in the as-received material. $\gamma-\mathrm{Y}_{2} \mathrm{Si}_{2} \mathrm{O}_{7}$ (JCPDS \#32-1448) was the only yttrium-silicon oxynitride phase detected and it primarily existed in multi-grain junctions. This phase has also been designated in the literature as the " $y$ "$\mathrm{Y}_{2} \mathrm{Si}_{2} \mathrm{O}_{7}$ phase and reported to be stabilized by cationic impurities (e.g., $\mathrm{Na}, \mathrm{Mg}$, Fe, etc.) [3-4].

Button-head tensile specimens (6 $\mathrm{mm}$ diameter and $35 \mathrm{~mm}$ gage length) were creep-ruptured at 110,125 , and $140 \mathrm{MPa}$ in ambient air $\left(25^{\circ} \mathrm{C}\right.$ and $\left.40-60 \% \mathrm{RH}\right)$ or in an argon ( $99.999 \%$ purity) environment at $1370^{\circ} \mathrm{C}$. All tests were conducted on electromechanical tensile test machines in electronic closed-loop load control. I† $^{\dagger}$ Specimens tested in ambient air were heated using a compact twozone, resistance-heated (MoSiz elements) furnace having six elements per zone. A specially-constructed vacuum furnacel (single-zone, graphite-resistance heating) was used for tests in argon. Specimen grips were positioned outside the hot zone in all tests. The grips and couplers were tensile load activated and were designed to minimize specimen bending. Specimen elongation was measured over a $25 \mathrm{~mm}$ gage length in both environments using a high temperature, contact extensometer that employed a capacitance sensor. Extensometer accuracy and stability of approximately $0.5 \mu \mathrm{m}$ and $2 \mu \mathrm{m}$ over the $25 \mathrm{~mm}$ gage length was achieved for the tests conducted in ambient air and argon, respectively. Personal computers were used to acquire load, load error, specimen elongation, and furnace temperature data as a function of time.

Optical and scanning electron microscopy (SEM) were used to examine the fracture surface of creep-ruptured specimens. Microstructural observation was hindered on fracture surfaces generated in ambient air because they were heavily oxidized. To circumvent this, the specimens that were creep-ruptured in ambient air were refractured at room temperature within their gage section to expose a microstructure deemed representative of the un-oxidized fracture surface.

Evidence of creep damage (e.g., cavities) and oxidation effects were sought.

$\dagger \quad$ Saint-Gobain / Norton Industrial Ceramics Corp., Northboro, MA.

i† Model 1380, Instron Corp., Canton, MA.

I Oxy-Gon Industries, Inc. Epsom, NH. 


\section{RESULTS \& DISCUSSION CREEP PERFORMANCE}

For the same stresses, the creep-rupture performance of NCX-5102 was different in ambient air from that in argon environments at $1370^{\circ} \mathrm{C}$. Creep-rupture tests conducted in argon showed consistently faster rates of creep and shorter lifetimes than those at the same stresses tested in ambient air. In a similar fashion, the creep rate of a hot-pressed silicon nitride was greater (and the lifetime shorter) in helium than in an air environment. [5] These trends are exhibited in the creep strain histories of the six specimens shown in Fig. 1. Values of the minimum creep rate, time to failure, and strain to failures for the six tested specimens are listed in Table I.

The creep or stress exponent (n) was determined for tests in both air and argon using the temperature-independent Norton-Bailey Equation:

$$
\dot{\varepsilon}=A_{0} \sigma^{n},
$$

where $\dot{\varepsilon}$ is the minimum creep rate, $A_{0}$ is a pre-exponential constant, and $\sigma$ is the tensile stress. Stress exponent values of 3.6 and 5.9 were determined for tests in air and argon, respectively, as shown in Fig. 2. The stress dependence of the minimum creep rate in air was less than half that in argon, while the minimum creep rate was almost an order of magnitude slower. Because of the relatively high value for the creep exponent, creep was believed to be due to diffusion $(n=1)$ accompanied by cavitation, grain separation by viscous flow, and possibly grain boundary sliding.

If this material follows a Monkman-Grant type relationship, then the faster minimum creep rates observed in argon tests would predict shorter lifetimes than in air tests, which in fact is what observed in Fig. 1. This appears to contradict earlier dynamic flexural results in which the flexure strength of a HIPed silicon nitride at $1370^{\circ} \mathrm{C}$ in argon was found to be independent of the stressing rate, while the flexure strength decreased with a decrease in stressing rate in air. [1] The discrepancies between the tensile creep results in the present study and the previously generated flexural dynamic fatigue results are currently under reconciliation.

\section{MICROSTRUCTURAL OBSERVATIONS}

$\mathrm{X}$-ray diffraction studies showed that the content of the residual $\alpha-\mathrm{Si}_{3} \mathrm{~N}_{4}$ had lessened as a result of the creep-rupture testing in air and argon. Cylindrical specimens $(\approx 1 \mathrm{~cm}$ long $)$ were sectioned out of the gage section of the specimens tested in air and argon at $125 \mathrm{MPa}$. The $\alpha-\mathrm{Si}_{3} \mathrm{~N}_{4}$ contents had decreased from $25 \%$ to $4 \%$ for the air creep-rupture test and from $30 \%$ to $9 \%$ for the argon creeprupture test. The specimen tested in air at $125 \mathrm{MPa}$ lasted $563 \mathrm{~h}$, while the specimen tested in argon lasted only $91 \mathrm{~h}$, so it is not known whether the higher $\alpha-\mathrm{Si}_{3} \mathrm{~N}_{4}$ content in the argon creep-ruptured specimen is because of the different environment or the longer time at temperature or both. The secondary phase $(\gamma-$ $\mathrm{Y}_{2} \mathrm{Si}_{2} \mathrm{O}_{7}$ ) identified in the as-received material was present in the creep-ruptured microstructures of both specimens. 
Fracture surfaces of specimens tested in air and argon at $125 \mathrm{MPa}$ are shown in Figs. 3 (a) and (b), respectively. Fracture surfaces of creep-rupture specimens tested in ambient air showed stress-corrosion cracking (SCC) damage zones. The growth of a SCC zone is tensile stress activated and is attributed to the coalescence of multi-grain junction and two-grain boundary cavities which are both highly concentrated in the near-surface volume of the specimen. [6] Similar zones of damage were also found in specimens tested in argon in the present study, see Fig. 3 (b). The microstructure within the SCC damage zone is compared with that outside the SCC damage zone in Fig. 4. Numerous arrows in Fig. 4 point to large regions of relatively high porosity within the SCC damage zone. Similar regions are not nearly as concentrated outside the SCC damage zone. In addition, there appeared to be a higher concentration of multi-grain junction cavities and pores within the SCC damage zone although this is not evident at the magnification shown in Fig. 4." This is a significant observation because this finding had always required deduction for creep-ruptured silicon nitride specimens tested in air because a thick oxidation layer would consume and hide the microstructure of the damage zone at this scale.

Polished $(0.25 \mu \mathrm{m})$ cross-sections of the creep-rupture specimens tested in air and argon at $125 \mathrm{MPa}$ are shown in Figs. 5 (a) and (b), respectively. These are the same two specimens whose fracture surfaces are shown in Figs, 3 (a) and (b) and are representative of all the creep-rupture specimens that were tested in the two different environments. The cross-section of the specimen tested in ambient air (Fig. 5(a)) shows a large, lightly-shaded annular region that had advanced radially inwards from the specimen's outer surface. This ring is conspicuously absent on the polished cross-section of the creep-rupture specimen tested in argon (Fig. 5(b)). This similar ring has been observed previously on polished crosssections of silicon nitride specimens mechanically tested at elevated temperatures in ambient air. [2,6-7] This conclusive evidence shows that the outer annular region is due to oxidation effects associated with ambient air testing.

This information about the annular region invokes the question, what is the significance of the annular region that forms in creep-rupture specimens tested in ambient air? The annular region in creep-ruptured specimens tested in ambient air coincides with a volume of material which contains a high concentration of multigrain junction cavities and pores. However, similar cavitation is found in the near-surface volume of creep-ruptured specimens tested in argon, yet no similar annular region is visible. This means that near-surface discoloration can be indicative of how far the advance of concentrated cavitation and void formation has advanced radially inwards. However, if an annular region is not visible (i.e., for creep-rupture tests conducted in argon), then it cannot be surmised that a front of cavitation and void formation in the multi-grain junctions in the near-surface volume of material is non-existent.

* There was actually a higher concentration of cavities and pores in the multi-grain junctions around the whole outer surface (i.e., the near-surface volume) of the creepruptured specimen compared to its central volume; however, the concentration of this porosity was even greater in the region of the SCC damage zone. 
The consistently faster creep rates and consequential shorter lifetimes of specimens creep-ruptured in argon is believed to be due to cation diffusion (or lack thereof) in the grain boundaries. Oxidation that occurs during creep-rupture tests in ambient air provides a driving force for impurity cations to diffuse towards the surface from the bulk via the grain boundaries. [8] In a similar vein, significant amounts of yttrium were found to diffuse towards the surface from the bulk via the grain boundaries in NCX-5102 silicon nitride during creep-rupture tests in ambient air. [6] The diffusion of cations towards the surface and their accumulation there reduces their concentration in the grain boundaries in the central volume of the specimen; this reduction of cations in the silicate-based grain boundaries effectively increases the grain boundary viscosity [9] and improves the creep resistance in the central volume over time. The lack of a driving force to cause the migration of cations in creep-rupture tests in argon provides no substantial "purification" effect in the grain boundaries within the bulk of the material. This explanation is in reference to the work by Clarke [10] in which it was reported that cation impurities remain in the grain boundaries of silicon nitride in a reducing atmosphere at elevated temperatures and that only an oxidation heat treatment can remove them. Consequently, this "purification" effect does not evolve during the creep-rupture tests in argon, the grain boundary viscosity in the central volume does not increase, and the creep resistance does not improve with time as it did in creep-rupture tests in air.

\section{CONCLUSIONS}

NCX-5102 silicon nitride creeps faster and exhibits shorter lifetimes in argon than in ambient air at $1370^{\circ} \mathrm{C}$ at stresses between $110-140 \mathrm{MPa}$. The stress dependence of the minimum creep rate of specimens tested in ambient air was about $60 \%$ of that for specimens tested in argon (3.6 versus 5.9 ), while the minimum rates were almost an order of magnitude slower for tests in air at equivalent tensile stresses.

The slower minimum creep rates in ambient air are believed to be due to impurity cation migration towards the specimen surface over time, which in effect increases the grain boundary viscosity in the central volume of the specimen, which in turn improves its creep resistance with time. The migration of cation impurities is not as active (or active at all) during creep-rupture testing in argon. Consequently, there is not the marked "purification" effect occurring in the grain boundaries in the central volume of the specimen with time and the creep resistance within the grain boundaries does not increase as significantly as it likely did for specimens tested in ambient air.

A macroscopically large SCC damage zone caused failure in all specimens creep-ruptured in both environments. At a microscopic scale, the SCC damage zone was found to contain a characteristically high concentration of multi-grain junction cavities and pores. Evidence suggests that the highly concentrated cavities and pores coalesced to form the macroscopically large SCC damage zone and fracture was ultimately produced.

\section{DISCLAIMER}

\footnotetext{
This report was prepared as an account of work sponsored by an agency of the United States Government. Neither the United States Government nor any agency thereof, nor any of their employees, makes any warranty, express or implied, or assumes any legal liability or responsibility for the accuracy, completeness, or usefulness of any information, apparatus, product, or process disclosed, or represents that its use would not infringe privately owned rights. Refermanufacturer, or specific commercial product, process, or service by trade name, trademark, mendation, or favoring by the not necessarily constitute or imply its endorsement, recomand opinions of authors the United States Government or any agency thereof. The views United States Government or any agency do not necessarily state or reflect those of the
} 


\section{ACKNOWLEDGMENTS}

The authors wish to thank Drs. K. Breder, K. C. Liu, and A. E. Pasto for reviewing the manuscript and for their helpful comments.

\section{REFERENCES}

[1] A. A. Wereszczak, K. Breder, and M. K. Ferber, "Role of Oxidation in the Time-Dependent Failure Behavior of Hot Isostatically Pressed Silicon Nitride at $1370^{\circ} \mathrm{C}, "$ J. Am. Cer. Soc., 76 [11] 2919-22 (1993).

[2] A. A. Wereszczak, T. P. Kirkland, K. Breder, M. K. Ferber, P. Khandelwal, "High Temperature Dynamic Fatigue Performance of a Hot Isostatically Pressed Silicon Nitride," In press, Mat. Sci. \& Engrg.

[3] W. E. Lee, C. H. Drummond III, G. E. Hilmas, and S. Kumar, "Microstructural Evolution in Near-Eutectic Yttrium Silicate Compositions Fabricated from a Bulk Melt and as an Intergranular Phase in Silicon Nitride," J. Am. Cer. Soc., 73 [12] 3575-79 (1990).

[4] J. T. Smith, "Temperature and Compositional Stability of a $\mathrm{Y}_{6} \mathrm{Si}_{6} \mathrm{O}_{21}$ Phase in Oxidized Si3N4," J. Am. Cer. Soc., 60 [9-10] 465-66 (1977).

[5] R. Kossowsky, D. G. Miller, and E. S. Diaz, "Tensile and Creep Strengths of Hot-Pressed Si3 N4," J. Mat. Sci., 10 983-97 (1975).

[6] A. A. Wereszczak, M. K. Ferber, T. P. Kirkland, K. L. More, M. R. Foley, R. L. Yeckley, "Evolution of Stress Failure Resulting from High Temperature Stress-Corrosion Cracking in a Hot Isostatically Pressed Silicon Nitride," In review J. Am. Cer. Soc.

[7] A. A Wereszczak, M. K. Ferber, and T. P. Kirkland, "Effects of Oxidation and Creep Damage Mechanisms on Creep Rupture Behavior in HIPed Silicon Nitrides," Ceram. Engrg. Sci. Proc., 15 [7-8] 49-56 (1994).

[8] D. R. Clarke and F. F. Lange, "Oxidation of $\mathrm{Si}_{3} \mathrm{~N}_{4}$ Alloys: Relation to Phase Equilibria in the System $\mathrm{Si}_{3} \mathrm{~N}_{4}-\mathrm{SiO}_{2}-\mathrm{MgO}$," J. Am. Cer. Soc., 63 [9-10] 586-93 (1980).

[9] W. D. Kingery, H. K. Bowen, and D. R. Uhlmann, Introduction to Ceramics, 2nd Edition, John Wiley \& Sons, New York, 1976.

[10] D. R. Clarke, "A Comparison of Reducing and Oxidizing Heat Treatments of Hot-Pressed Silicon Nitride," J. Am. Cer. Soc., 66 [2] 92-95 (1983).

Table 1. Summary of creep-rupture results.

\begin{tabular}{|c|c|c|c|c|}
\hline Environment & $\begin{array}{l}\text { Tensile } \\
\text { Stress } \\
\text { (MPa) }\end{array}$ & $\begin{array}{l}\text { Minimum } \\
\text { Strain Rate } \\
\left(s^{-1}\right)\end{array}$ & $\begin{array}{l}\text { Time To } \\
\text { Failure } \\
\text { (h) }\end{array}$ & $\begin{array}{c}\text { Strain To } \\
\text { Failure } \\
(\mu \mathrm{m} / \mathrm{m})\end{array}$ \\
\hline AIR & 110 & $2.3 \times 10^{-9}$ & 978 & 12880 \\
\hline AIR & 125 & $2.9 \times 10^{-9}$ & 563 & 9760 \\
\hline AIR & 140 & $5.5 \times 10^{-9}$ & 361 & 12460 \\
\hline ARGON & 110 & $6.7 \times 10^{-9}$ & 206 & 11360 \\
\hline ARGON & 125 & $1.4 \times 10^{-8}$ & 91 & 14760 \\
\hline ARGON & 140 & $2.8 \times 10^{-8}$ & 58 & 11980 \\
\hline
\end{tabular}




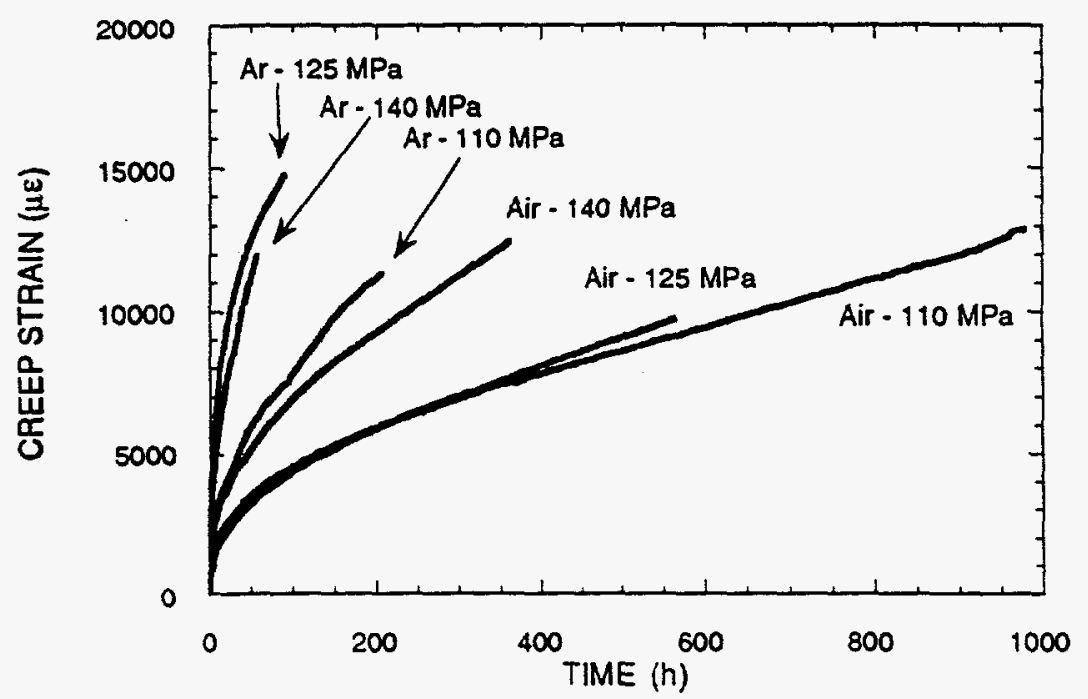

Fig. 1. NCX-5102 silicon nitride crept faster and had shorter lifetimes in argon than in ambient air at $1370^{\circ} \mathrm{C}$.

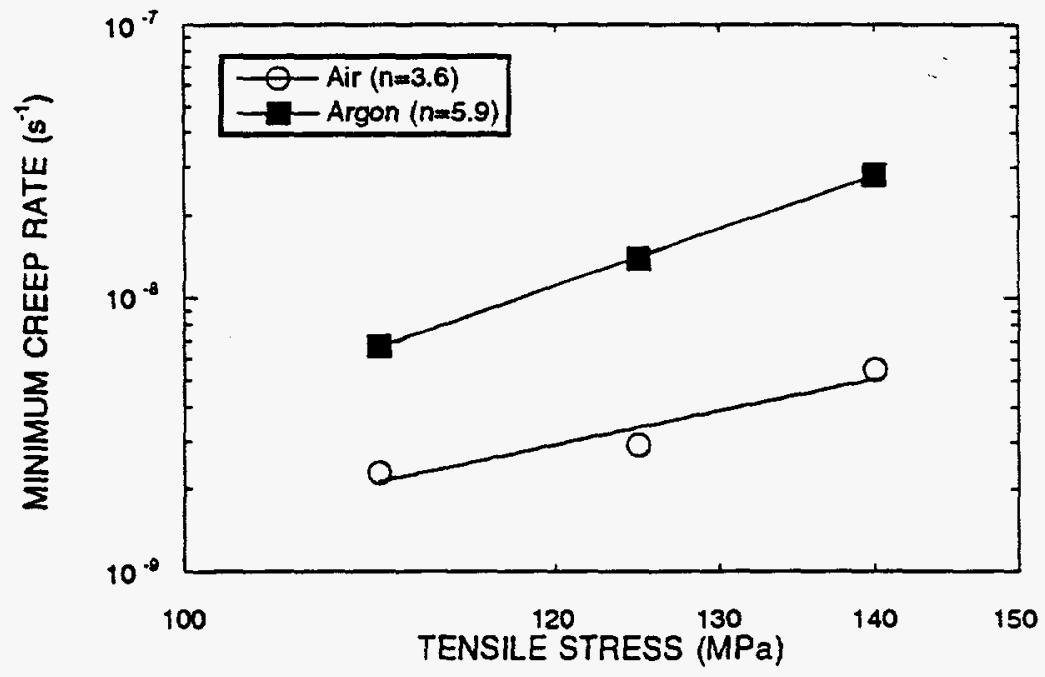

Fig. 2. The stress dependence of the minimum creep rate of tests in ambient air was about $60 \%$ (3.6 versus 5.9) of that for tests in argon, while the minimum creep rates were almost an order of magnitude slower for the tests in ambient air. 

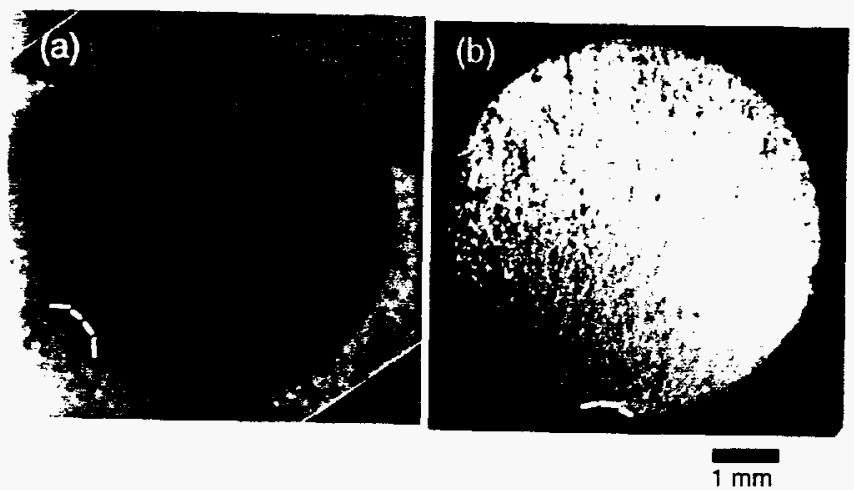

Fig. 3. Fracture surfaces of creep-rupture specimens tested in ambient air (a) and argon (b) at $1370^{\circ} \mathrm{C}$ and $125 \mathrm{MPa}$. The crack fronts of the SCC damage zones are depicted in both images.

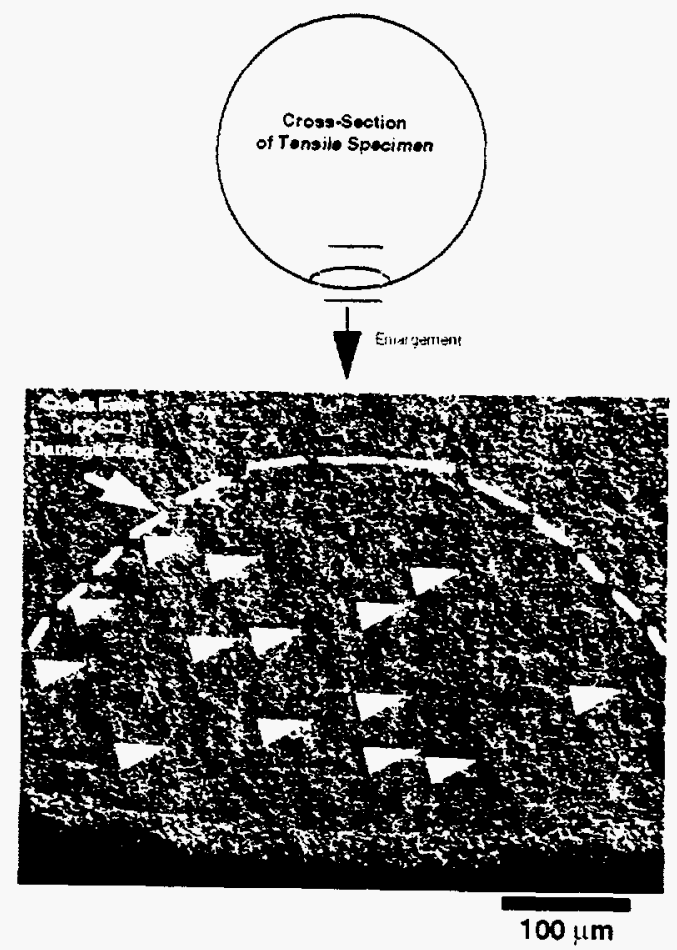

Fig. 4. The microstucture within the SCC damage zone contained relatively large regions (indicated by the arrows) of high porosity whereas similar regions were not nearly as concentrated outside the SCC damage zone. 


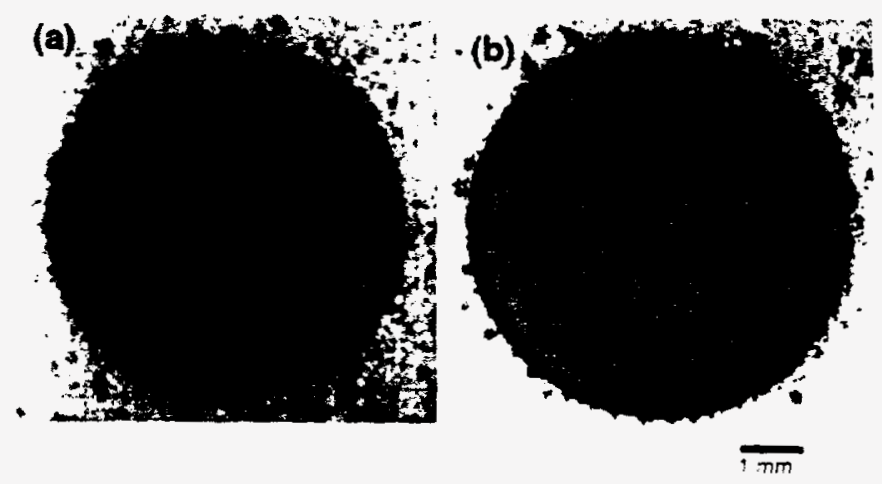

Fig. 5. Polished surfaces of creep-ruptured specimens tested in ambient air (a) and argon (b) at $1370^{\circ} \mathrm{C}$ and $125 \mathrm{MPa}$. These are the same specimens whose fracture surfaces are shown in Figs. 3a-b, respectively. The rings are of the same order of thickness as the radial extent of the SCC damage zones shown in Fig. 3. 